\title{
Presynaptic Mechanism Underlying cAMP-Dependent Synaptic Potentiation
}

\author{
Masahiro Kaneko and Tomoyuki Takahashi \\ Department of Neurophysiology, University of Tokyo Graduate School of Medicine, Tokyo 113-0033, Japan
}

The adenylyl cyclase activator forskolin presynaptically facilitates synaptic transmission at many synapses, but the exact intracellular mechanism underlying this effect is not known. We studied this issue at the calyx of Held, where it is possible to make simultaneous presynaptic and postsynaptic whole-cell recordings. Bath application of forskolin or intracellular application of cAMP into presynaptic terminals strongly potentiated EPSCs. The forskolin-induced synaptic potentiation was associated with increases in release probability $(P)$ and number of releasable synaptic vesicles $(N)$. Forskolin had no effect on the peak amplitudes of presynaptic $\mathrm{Ca}^{2+}$ currents or $\mathrm{K}^{+}$ currents, suggesting that the main target of cAMP resides in downstream of $\mathrm{Ca}^{2+}$ influx. Intracellular application of the selective Epac agonist 8-(4-chlorophenylthio)-2'-O-methyl-cAMP into presynaptic terminals potentiated EPSCs, suggesting that Epac is the main target of cAMP-induced synaptic potentiation. We conclude that an increase in cAMP concentration in the nerve terminal facilitates transmitter release by increasing both release probability and number of releasable vesicles via activating the Epac pathway at the calyx of Held.

Key words: cAMP; synaptic potentiation; release probability; Epac; calyx of Held; presynaptic

\section{Introduction}

Short-term and long-term changes of synaptic efficacy are thought to play pivotal roles in cognition, learning, and memory formation. cAMP is one of the best-studied second messengers. It activates protein kinase $\mathrm{A}$ (PKA), thereby facilitating transmitter release for a sustained period (Chavez-Noriega and Stevens, 1994; Weisskopf et al., 1994; Capogna et al., 1995; Salin et al., 1996; Trudeau et al., 1996). This effect of cAMP, together with that on cAMP response element-binding protein, is thought to underlie long-term potentiation of synaptic efficacy and memory consolidation (Bailey et al., 1996; Silva et al., 1998). Recently, however, PKA-independent actions of cAMP, which facilitate releases of transmitters or hormones, have been reported. For example, at the crayfish neuromuscular junction, cAMP activates presynaptic $I_{\mathrm{h}}$ channels, thereby increasing transmitter release (Beaumont and Zucker, 2000). In pancreatic cells, the cAMPsensitive guanine nucleotide-exchanging factor (GEF; also called Epac) interacts with Rim2, thereby enhancing insulin secretion (Ozaki et al., 2000; Kashima et al., 2001; Eliasson et al., 2003).

At synapses, despite many studies using membrane permeable cAMP analogs or adenylyl cyclase activators, relatively little is known for the mechanism underlying the cAMP-dependent synaptic potentiation. At the calyx of Held, visually identified in brainstem slices of rodents, one can load various molecules directly into the giant presynaptic terminal via patch pipettes dur-

\footnotetext{
Received March 18, 2004; revised April 22, 2004; accepted April 23, 2004.

This study was supported by Grant-in-Aid for Specially Promoted Research from the Ministry of Education, Culture, Sports, Science, and Technology. We thank Taro Ishikawa for comments on this manuscript.

Correspondence should be addressed to Tomoyuki Takahashi, Department of Neurophysiology, University of Tokyo Graduate School of Medicine, 7-3-1 Hongo, Bunkyo-ku, Tokyo 113-0033, Japan. E-mail: ttakahas-tky@umin.ac.jp.

DOI:10.1523/JNEUROSCI.0999-04.2004

Copyright $\odot 2004$ Society for Neuroscience $\quad 0270-6474 / 04 / 245202-07 \$ 15.00 / 0$
}

ing simultaneous presynaptic and postsynaptic whole-cell recordings (Takahashi et al., 1998; Hori et al., 1999; Ishikawa et al., 2002; Yamashita et al., 2003). At this synapse, the adenylyl cyclase activator forskolin potentiates postsynaptic responses evoked by presynaptic $\mathrm{Ca}^{2+}$ currents (Sakaba and Neher, 2001). In the present study, we examined further the mechanism underlying the cAMP-dependent synaptic potentiation. Our results indicate that cAMP facilitates transmitter release via activating the PKAindependent Epac pathway in the nerve terminal.

\section{Materials and Methods}

Preparation and solutions. All experiments were performed in accordance with the guidelines of the Physiological Society of Japan. Wistar rats, 7-22 d of age [postnatal day (P) 7-P22], were killed by decapitation under halothane anesthesia. Most experiments (unless otherwise noted) were performed on P7-P9 rats. Transverse brainstem slices (180-200 $\mu \mathrm{m}$ thick) containing the medial nucleus of the trapezoid body (MNTB) were cut using a slicer (PRO7; Dosaka, Kyoto, Japan). Slices were incubated at $36-37^{\circ} \mathrm{C}$ for $1 \mathrm{hr}$ and then maintained at room temperature $\left(22-26^{\circ} \mathrm{C}\right)$. Postsynaptic MNTB principal neurons and presynaptic terminals were visually identified with a $40 \times$ or $60 \times$ water immersion objective (Olympus Optical, Tokyo, Japan) attached to an upright microscope (Axioskop; Zeiss, Oberkochen, Germany). The standard artificial CSF (aCSF) for perfusion contained (in $\mathrm{mm}$ ): $125 \mathrm{NaCl}, 2.5 \mathrm{KCl}, 26$ $\mathrm{NaHCO}_{3}, 1.25 \mathrm{NaH}_{2} \mathrm{PO}_{4}, 2 \mathrm{CaCl}_{2}, 1 \mathrm{MgCl}_{2}, 10$ glucose, 3 myoinositol, 2 sodium pyruvate, and 0.5 ascorbic acid, $\mathrm{pH} 7.3$ with $95 \% \mathrm{O}_{2} / 5 \% \mathrm{CO}_{2}$, 310-320 mOsm. The aCSF also routinely contained bicuculline methiodide (10 $\mu \mathrm{M}$; Sigma, St. Louis, MO) and strychnine hydrochloride (0.5 $\mu \mathrm{M}$; Sigma) to block inhibitory synaptic responses. To minimize saturation of postsynaptic AMPA receptors, in most experiments, $\mathrm{CaCl}_{2}$ in the aCSF was reduced to $1 \mathrm{~mm}$ and $\mathrm{MgCl}_{2}$ was increased to $2 \mathrm{~mm}$, and kynurenic acid (Tocris Cookson, Bristol, UK) was added at 0.2 or $2.0 \mathrm{~mm}$, with the lower concentration used for simultaneous presynaptic and postsynaptic recordings, in which the amplitude of EPSCs is often smaller than that in single postsynaptic recordings. Except for recording NMDA 
receptor-mediated EPSCs (NMDA-EPSCs), the NMDA receptor blocker D-AP-5 (50 $\mu \mathrm{M}$; Tocris Cookson) was included in the aCSF. For postsynaptic recordings, pipette solution contained (in $\mathrm{mm}$ ): $120 \mathrm{CsF}, 30 \mathrm{CsCl}$, 10 HEPES, 5 EGTA, $1 \mathrm{MgCl}_{2}$, and $5 \mathrm{~N}$-(2,6-Diethylphenylcarbamoylmethyl)-triethylammonium chloride ( $N$-ethyl bromide quaternary salt; Alomone Labs, Jerusalem, Israel), with pH adjusted to 7.3 with $\mathrm{CsOH}$ (295-300 mOsm). For simultaneous presynaptic and postsynaptic recordings and holding current recordings, the presynaptic pipette solution contained (in $\mathrm{mm}$ ): 77.5 potassium gluconate, 20 sodium gluconate, $32.5 \mathrm{KCl}, 10$ potassium glutamate, 10 dipotassium phosphocreatine, $3 \mathrm{Mg}$-ATP, $0.5 \mathrm{Na}-\mathrm{GTP}, 0.5 \mathrm{EGTA}, 1 \mathrm{MgCl}_{2}$, and 10 HEPES, pH 7.3 adjusted with $\mathrm{KOH}$ (295-300 Osm). For intracellular applications of cAMP or 8-(4-chlorophenylthio)-2'-O-methyl (8CPT2Me)-cAMP sodium salt (0.5 mM; Biolog, Bremen Germany), these drugs were included in the presynaptic pipette replacing equimolar sodium gluconate. For recording presynaptic $\mathrm{Ca}^{2+}$ currents, the aCSF contained $10 \mathrm{~mm}$ tetraethylammomium (TEA) chloride and $1 \mu \mathrm{M}$ tetrodotoxin (TTX), and the presynaptic pipette solution contained (in mM): $110 \mathrm{CsCl}, 10$ TEA chloride, 40 HEPES, 0.5 EGTA, $1 \mathrm{MgCl}_{2}$, 2 Mg-ATP, 12 disodium phosphocreatine, and 0.5 GTP, pH 7.3 adjusted with $\mathrm{CsOH}$ (295-300 Osm). The pipette solution for recording presynaptic $\mathrm{K}^{+}$currents contained (in $\mathrm{mM}$ ): 97.5 potassium gluconate, $32.5 \mathrm{KCl}, 12$ dipotassium phosphocreatine, $3 \mathrm{Mg}$ ATP, $0.5 \mathrm{Na}$-GTP, $1 \mathrm{MgCl}_{2}$, 5 EGTA, and 10 HEPES, pH 7.3 adjusted with $\mathrm{KOH}(295-300$ Osm). TTX ( $1 \mu \mathrm{M})$ was added to the aCSF for recording presynaptic $\mathrm{K}^{+}$currents and holding currents.

Recording and data analysis. Whole-cell recordings were made using a patch-clamp amplifier (Axopatch 200B or Multiclamp 700A; Axon Instruments, Foster City, CA). The resistance of patch pipette was 4-8 M $\Omega$ for presynaptic recordings and 1.5-3 $\mathrm{M} \Omega$ for postsynaptic recordings. The series resistance of presynaptic recordings (8-18 $\mathrm{M} \Omega$ ) was compensated by $70-90 \%$ in voltage-clamp experiments. The holding potential under voltage clamp was $-70 \mathrm{mV}$ for postsynaptic recording and -80 $\mathrm{mV}$ for presynaptic recording unless otherwise noted. The liquid junction potential between pipette and external solution was not corrected unless otherwise noted. EPSCs were evoked at $0.033 \mathrm{~Hz}$ by extracellular stimulation using a bipolar tungsten electrode positioned halfway between the midline and the MNTB. EPSCs derived from the calyx of Held were identified as those evoked in an all-or-none manner for graded stimulus intensity with amplitude $>1 \mathrm{nA}$ at $-70 \mathrm{mV}$ (Forsythe and Barnes-Davies, 1993). The mean amplitude of EPSCs in the standard aCSF was $4.7 \pm 1.0 \mathrm{nA}($ mean $\pm \mathrm{SEM} ; n=9)$. In the low-Ca ${ }^{2+}(1 \mathrm{mM})$ high- $\mathrm{Mg}^{2+}(2 \mathrm{~mm})$ aCSF added with kynurenate ( $\left.2 \mathrm{~mm}\right)$, the EPSC amplitude was reduced to $10 \pm 1.5 \%(n=17)$. The records were low-pass filtered at $5-6 \mathrm{kHz}$ and digitized at $50 \mathrm{kHz}$ by an analog-to-digital converter (Digidata 1320 A or Digidata $1322 \mathrm{~A}$ ) with pClamp8 software (Axon Instruments). The weighted mean time constant for (+)-5methyl-10,11-dihydro-5H-dibenzo [a,d] cyclohepten-5,10-imine maleate (MK-801) block $\left(\tau_{\mathrm{m}}\right)$ was calculated from the fast $\left(\tau_{\mathrm{f}}\right)$ and slow $\left(\tau_{\mathrm{s}}\right)$ time constants and their amplitude ratios $\left(a_{\mathrm{f}}\right.$ and $\left.a_{\mathrm{s}}\right)$ as: $\tau_{\mathrm{m}}=a_{\mathrm{f}} \tau_{\mathrm{f}}+a_{\mathrm{s}} \tau_{\mathrm{s}}$. All values in the present study are given as mean \pm SEM, and the significance in difference was evaluated by Student's paired two-tailed $t$ test or two-sample two-tailed $t$ test.

Drugs. Forskolin, 1, 9-dideoxy-forskolin (Dd-forskolin), cAMP sodium salt, dipotassium phosphocreatine, hexahydro-10-hydroxy-9-methyl-1oxo-9,12-epoxy-1H-diindolo[1,2,3-fg:3Ç,2Ç,1Ç-kl]pyrrolo[3,4-i] [1,6] benzodiazocine-10-carboxylic acid hexyl ester (KT5720), and ryanodine (high purity) were purchased from Calbiochem (La Jolla, CA). D-AP-5, 2,3-dioxo-6-nitro-1,2,3,4-tetrahydrobenzo[f] quinoxaline-7-sulfonamide (NBQX), and kynurenic acid were purchased from Tocris Cookson. MK801 was purchased from Sigma, $N$-[2-( $p$-bromocinnamylamino)ethyl]5-isoquinolinesulfonamide (H-89) was purchased from Seikagaku Kogyo (Tokyo, Japan), and phorbol 1,2-dibutrate was purchased from Biomol (Plymouth Meeting, PA).

\section{Results}

\section{Potentiation of EPSCs by forskolin}

The adenylyl cyclase activator forskolin $(50 \mu \mathrm{M})$ potentiated EPSCs at the calyx of Held (Fig. $1 A$ ). Although its effect was small in the standard aCSF $(27 \pm 2.5 \% ; n=4)$ (Fig. $1 B, C)$, much greater potentiation $(335 \pm 64 \% ; n=7)$ was observed after reducing the amplitude of EPSCs in low- $\mathrm{Ca}^{2+}(1 \mathrm{~mm})$ high- $\mathrm{Mg}^{2+}(2 \mathrm{~mm})$ aCSF added with the low affinity glutamate receptor antagonist kynurenate (2 mM) (Fig. 1 $A-D$ ). Similar magnitude of potentiation could be produced by forskolin when higher concentration of kynurenate $(5 \mathrm{~mm})$ was simply added to the standard aCSF $(252 \pm 60 \% ; n=4)($ Fig. $1 B, C)$ or when the $\mathrm{Ca}^{2+} / \mathrm{Mg}^{2+}$ ratio in the aCSF was greatly reduced (to 0.16 ) without adding kynurenate $(266 \pm 105 \% ; n=4)$ (Fig. $1 B, C)$. The magnitude of EPSC potentiation by forskolin showed an inverse relationship with the initial amplitude of EPSCs recorded under different conditions $(r=-0.78)$ (Fig. 1C), suggesting that the synaptic potentiation is normally masked by saturation and desensitization of postsynaptic AMPA receptors by transmitter glutamate (Taschenberger et al., 2002; Wong et al., 2003). The magnitude of EPSC potentiation by forskolin was concentration dependent (Fig. 1D), with the $50 \% \mathrm{EC}_{50}$ being $2.3 \mu \mathrm{M}$. In the presence of forskolin, EPSCs remained potentiated without a sign of decline for at least $60 \mathrm{~min}$ (data not shown). The inactive analog Dd-forskolin $(50 \mu \mathrm{M})$ had no effect $(-0.3 \pm 6.2 \% ; n=3)$ (Fig. $1 A)$. Forskolin also increased the frequency of miniature EPSCs (mEPSCs) by $171 \pm 8.3 \%$ ( $n=$ 4) but had no significant effect on their amplitude (Fig. 1E), suggesting that its site of action is presynaptic, as previously reported at this (Sakaba and Neher, 2001) and other (ChavezNoriega and Stevens, 1994; Capogna et al., 1995; Trudeau et al., 1996) synapses. At the calyx of Held, the facilitatory effect of forskolin was robust at P8-P9 but became weaker as animals matured (Fig. $1 \mathrm{~F}$ ), with the magnitude of potentiation by forskolin $(50 \mu \mathrm{M})$ being $184 \pm 60 \%$ at P14-P15 $(n=6)$ and $76 \pm 31 \%$ at P21-P22 $(n=4)$.

\section{Potentiation of EPSCs by cAMP}

Although forskolin or membrane permeable cAMP analogs facilitate transmitter release at many synapses, it has not been demonstrated that cAMP by itself can potentiate synaptic transmission. To examine this, we made simultaneous presynaptic and postsynaptic whole-cell recordings and loaded cAMP into the calyceal nerve terminal. After recording EPSCs of stable amplitude evoked by presynaptic action potentials (Fig. $2 \mathrm{Aa}$ ), we retracted the presynaptic pipette and made another whole-cell recording from the same presynaptic terminal using a new pipette containing cAMP $(500 \mu \mathrm{M})$. This pipette replacement causes no artificial effect on the EPSC amplitude (Takahashi et al., 1998). When cAMP was loaded from a new pipette, EPSCs underwent a marked potentiation (by $160 \pm 47 \% ; n=5$ ) (Fig. $2 A b, B$ ). Intracellular cAMP application at a lower concentration $(10 \mu \mathrm{M})$ had no appreciable effect (data not shown). Thus, an increase in cAMP concentration in the nerve terminal did enhance transmitter release.

Intracellular cAMP loading also depolarized presynaptic terminals (Fig. $2 B)$ on average by $7.6 \pm 2 \mathrm{mV}(n=5)$. Because presynaptic depolarization can potentiate EPSC amplitude (Turecek and Trussel, 2001), we examined in separate experiments to what extent presynaptic depolarization contributes to EPSC potentiation by passing currents through a patch pipette. When we depolarized presynaptic terminals by $6-7 \mathrm{mV}$, EPSCs were only slightly potentiated (Fig. $2 C)(13 \pm 5 \% ; n=5)$. Depolarization of the nerve terminal by $13 \mathrm{mV}$ also increased the EPSC amplitude by $35 \pm 13 \%(n=4)$. Thus, the contribution of presynaptic depolarization to cAMP-induced synaptic potentiation (160\%) is minor. 
Forskolin increases the number of releasable vesicles and release probability

Enhancement of evoked transmitter release can arise from an increase in the number of readily releasable quanta (synaptic vesicles) $(N)$ or an increase in release probability $(P)$. To examine which mechanism underlies the forskolin-induced EPSC potentiation, we first used the method of high-frequency stimulation (Schneggenburger et al., 1999; Iwasaki and Takahashi, 2001; Taschenberger et al., 2002). In this method, assuming that the depression is primarily caused by the depletion of readily releasable quanta, $N$ multiplied by mean quantal size $(q)$ can be estimated from zero time intercept of a line fitted to a cumulative amplitude plot of EPSCs (Fig. $3 B$ ), and $P$ can be estimated from the first EPSC amplitude devided by $\mathrm{Nq}$. Although this method in our recording condition (in low- $\mathrm{Ca}^{2+}$ aCSF containing 2 mu kynurenate) does not give us absolute $N$ values, it can still indicate the magnitudes of change in $N$ and $P$ caused by forskolin. Forskolin $(50 \mu \mathrm{M})$ potentiated the first few EPSCs during a train of tetanic stimulation $(100 \mathrm{~Hz})$ (Fig. 3A). Cumulative amplitude histograms before and after forskolin application (Fig. 3B) indicated that forskolin increased $N q$ by $179 \pm 54 \%$ on average $(n=6$; $p<0.05$, paired $t$ test) (Fig. $3 C$ ) and $P$ by $113 \pm 13 \%(n=6 ; p<0.05)$ (Fig. $3 D)$. Given no effect of forskolin on $q$ (Fig. $1 E$ ), these results suggest that forskolin increases both the number of readily releasable quanta and release probability.

We further examined whether forskolin increases $P$ using MK-801, an openchannel blocker of NMDA receptors (Hessler et al., 1993; Rosenmund et al., 1993; Iwasaki and Takahashi, 2001). In this method, $P$ can be deduced from the blocking rate of NMDA receptors by MK-801. NMDA-EPSCs were recorded at a holding potential of $+40 \mathrm{mV}$ in the presence of the AMPA receptor blocker NBQX $(10 \mu \mathrm{M})$. After confirming a stable baseline in the amplitude of NMDA-EPSCs, we stopped stimulation and bath-applied MK-801 (40 $\mu \mathrm{M})$. After $5 \mathrm{~min}$, we resumed stimulation (at $0.033 \mathrm{~Hz}$ ) in the presence of MK-801. Every time after stimulation, the amplitude of NMDA-EPSCs became smaller. From five such experiments, the time course of decline could be fitted by a double exponential function, with a fast time constant $\left(\tau_{\mathrm{f}}\right)$ of $89 \sec \left(\mathrm{a}_{\mathrm{f}}, 77 \%\right)$ and a slow time constant $\left(\tau_{\mathrm{s}}\right)$ of $403 \mathrm{sec}$ with a weighted mean time constant $\left(\tau_{\mathrm{m}}\right)$ of $161 \mathrm{sec}$. In the presence of forskolin $(50 \mu \mathrm{M})$, the fast and slow time constants were $47 \sec \left(\mathrm{a}_{\mathrm{f}}\right.$, $89 \%)$ and $499 \sec \left(\tau_{\mathrm{m}}, 88 \mathrm{sec}\right)$, respectively (Fig. 4$)$. Thus, forskolin accelerated the fast time constant and also apparently in-
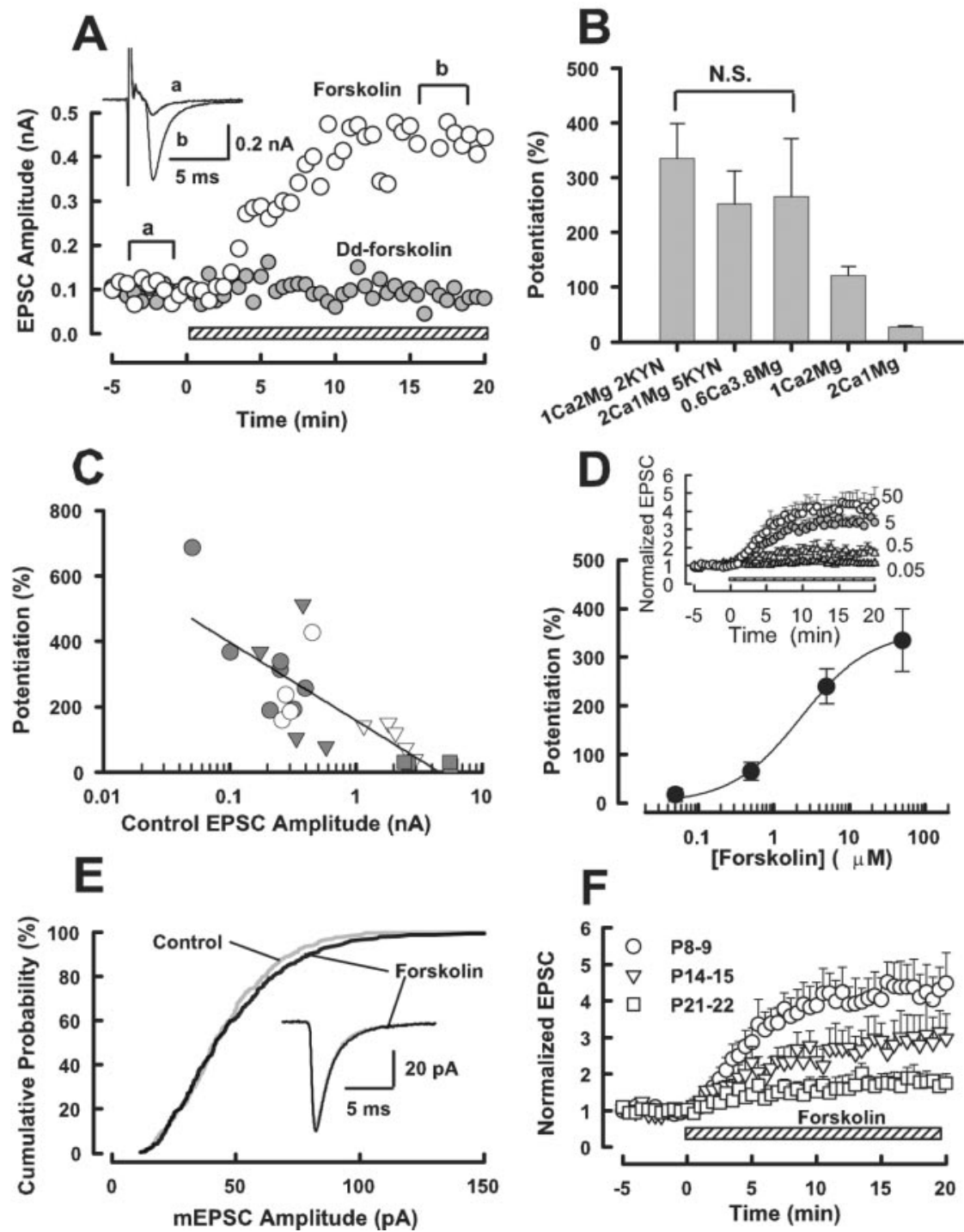

Figure 1. Potentiation of EPSCs by forskolin. A, Bath application of forskolin $(50 \mu \mathrm{m} ; \bigcirc)$ potentiated EPSCS, although the inactive analog Dd-forskolin ( ) had no such effect. Hatched bars in $A, D$, and $F$ indicate the period of drug application, which was started at time 0 . Averaged EPSCs $(n=5)$ sampled before $(a)$ and after $(b)$ forskolin application are superimposed in the inset. The aCSF contained $1 \mathrm{~mm} \mathrm{Ca}{ }^{2+}, 2 \mathrm{~mm} \mathrm{Mg}^{2+}$, and $2 \mathrm{~mm}$ kynurenate. $B$, Mean magnitudes of potentiation (error bars; $\pm S E M$ ) induced by forskolin $(50 \mu \mathrm{M})$ in $1 \mathrm{~mm} \mathrm{Ca}^{2+}, 2 \mathrm{~mm} \mathrm{Mg}{ }^{2+}, 2 \mathrm{~mm}$ kynurenate $(n=7 ; C, 0), 2 \mathrm{~mm} \mathrm{Ca}{ }^{2+}, 1 \mathrm{~mm} \mathrm{Mg}^{2+}, 5 \mathrm{~mm}$ kynurenate $(n=4 ; C, O), 0.6 \mathrm{~mm} \mathrm{Ca}^{2+}, 3.8 \mathrm{~mm} \mathrm{Mg}^{2+}(n=4 ; C, \nabla), 1 \mathrm{~mm} \mathrm{Ca}^{2+}, 2 \mathrm{~mm} \mathrm{Mg}^{2+}(n=5 ; C, \nabla)$, and $2 \mathrm{~mm} \mathrm{Ca}^{2+}$, $1 \mathrm{~mm} \mathrm{Mg}^{2+}(n=4, C, \square)$. There was no significant difference (N.S.) between values in a bracket (ANOVA; $\left.p>0.5\right)$. The magnitude of potentiation in $1 \mathrm{~mm} \mathrm{Ca}^{2+}, 2 \mathrm{~mm} \mathrm{Mg}^{2+}$ was $121 \pm 17 \%$ (see Results for values in other conditions). C, An inverse relationship between the initial EPSC amplitude (abscissa) and the magnitude of forskolin-induced potentiation (ordinate, $r=$ -0.78 ) for data obtained from different conditions indicated in B.D, The concentration dependence of forskolin effect in the aCSF containing $1 \mathrm{~mm} \mathrm{Ca}^{2+}, 2 \mathrm{~mm} \mathrm{Mg}{ }^{2+}, 2 \mathrm{~mm}$ kynurenate. Ordinate indicates the percentage of EPSC potentiation measured $15 \mathrm{~min}$ after forskolin application. A curve fit to data points represents the equation; the magnitude of potentiation: $(\%)=$ [maximal potentiation $] /\left[1+\mathrm{EC}_{50}\right.$ /forskolin concentration) $\left.{ }^{\mathrm{n}}\right]$, where the maximal potentiation is $353 \%, \mathrm{EC}_{50}$ is $2.3 \mu \mathrm{M}$, and Hill coefficient is 0.95 . The time plots of EPSC potentiations induced by forskolin of different concentrations ( $4-7$ cells each) are shown in the inset with the EPSC amplitude being normalized to control before forskolin application. E, Cumulative amplitude histograms of spontaneous $\mathrm{mEPSC}$ s recorded in the standard aCSF in the presence of TTX (1 $1 \mu \mathrm{M})$. Sample traces are $\mathrm{mEPSC}$ s averaged from 300 events before and after forskolin $(50 \mu \mathrm{m})$ application (completely superimposed). There was no significant difference in the distribution profile of mEPSC amplitude between the presence and absence of forskolin (Kolmogorov-Smirnov test; $p>0.5$ ). $F$, EPSC potentiation induced by forskolin $(50 \mu \mathrm{M})$ at different postnatal ages. Data are derived from four to seven cells. The potentiation at P21-P22 was significantly smaller than that at P8 $-\mathrm{P9}$ ( $p<0.05$; two sample $t$ test). The aCSF contained $1 \mathrm{~mm}$ $\mathrm{Ca}^{2+}, 2 \mathrm{~mm} \mathrm{Mg}^{2+}$, and $2 \mathrm{~mm}$ kynurenate.

creased the proportion of the fast component, thereby shortening $\tau_{\mathrm{m}}$ by 1.83 -fold. Because $P$ is inversely proportional to the decay time constant in the MK-801 experiments (Rosenmund et al., 1993), these results suggest that forskolin increased $P$ on average 
A

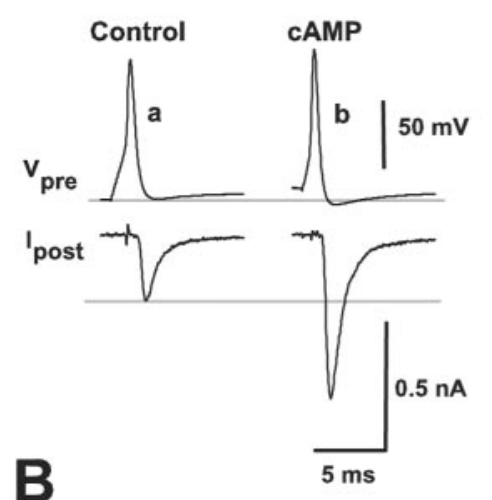

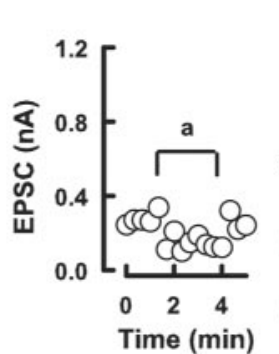
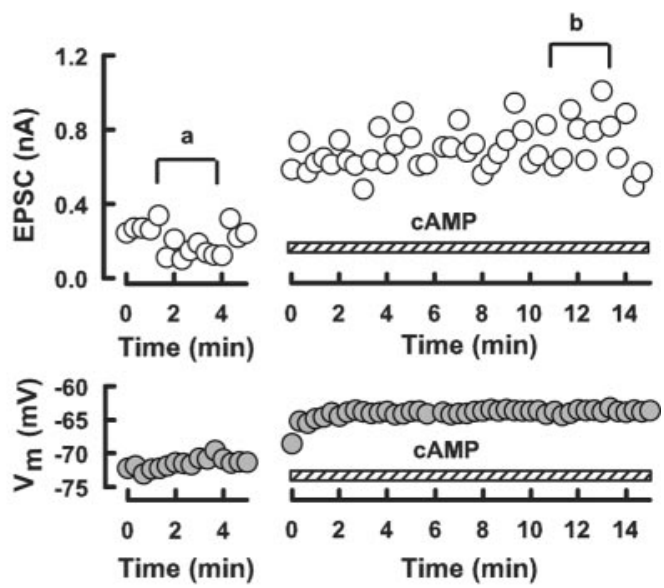
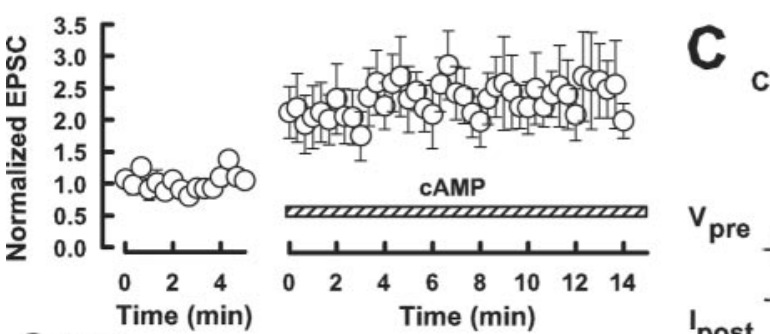

Control
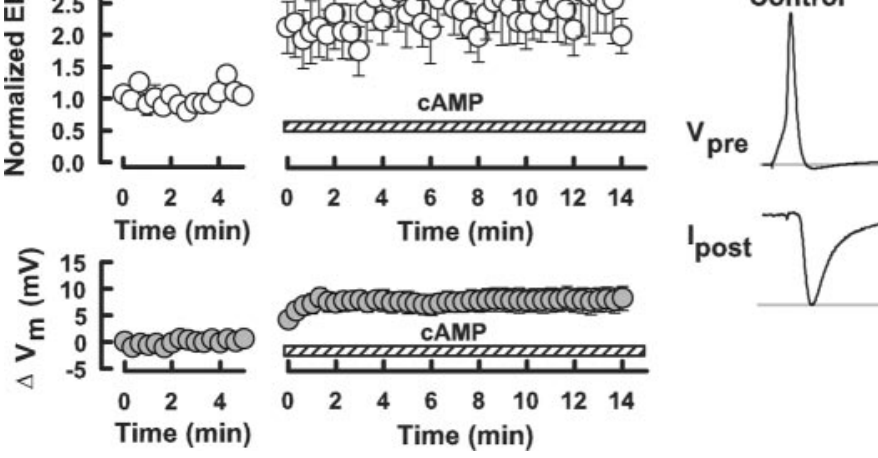

Figure 2. Intracellular application of CAMP into the calyceal terminal potentiated EPSCS. A, EPSCs are evoked by presynaptic action potentials in simultaneous presynaptic and postsynaptic recording ( $a$ ). After retracting a presynaptic pipette, whole-cell recording was made again from the same terminal with a new patch pipette containing CAMP (500 $\mu \mathrm{m}$; hatched bars). This caused a potentiation of EPSCS ( $b$, open circles). Sample records of presynaptic action potentials $\left(V_{\text {pre }}\right)$ and EPSCs $\left(l_{\text {post }}\right)$ are averaged, each from 10 consecutive records before $(a)$ and after $(b)$ intracellular CAMP application. The nerve terminal underwent a depolarization after CAMP application (filled circles). B, Data summarized from five experiments for the EPSC potentiations (open circles) and presynaptic depolarizations (filled circles) caused by CAMP. C, An example showing that presynaptic depolarization by $6.1 \mathrm{mV}$ by passing currents caused only $19 \%$ increase in EPSC amplitude.

by $83 \%$. This magnitude of increase in $P$ is comparable with that estimated from the high-frequency stimulation method (113\%) (Fig. 3).

\section{The effect of forskolin on presynaptic ionic conductance}

Given that forskolin increases $P$, we examined whether it might increase presynaptic $\mathrm{Ca}^{2+}$ influx by activating $\mathrm{Ca}^{2+}$ channels or inhibiting $\mathrm{K}^{+}$channels. As shown in Figure $5 A$, forskolin (50 $\mu \mathrm{M})$ had no effect on the presynaptic voltage-dependent $\mathrm{Ca}^{2+}$ currents at all membrane potentials examined. Also, forskolin had no effect on the peak amplitude of presynaptic voltagedependent $\mathrm{K}^{+}$currents, whereas it enhanced inactivation of $\mathrm{K}^{+}$ currents (Fig. $5 B$ ). The magnitude of $\mathrm{K}^{+}$currents attenuated at $90 \mathrm{msec}$ after depolarization (to $0 \mathrm{mV})$ was $9.2 \pm 1.4 \%(n=4$; $p<0.01$ in paired $t$ test). However, this effect cannot affect $\mathrm{Ca}^{2+}$ influx evoked by an action potential having a half width of 0.5 msec (Taschenberger and von Gersdorff, 2000). Consistent with the presynaptic depolarizing effect of cAMP (Fig. 2), forskolin depolarized the nerve terminal by $6.8 \pm 1 \mathrm{mV}(n=5)$ in the current-clamp mode and caused a sustained inward current of $55 \pm 8.2 \mathrm{pA}(n=4)$ under voltage clamp (Fig. $5 C) . \mathrm{Ba}^{2+}(1 \mathrm{~mm})$ by itself induced an inward current by blocking inward rectifying potassium currents (Takahashi et al., 1998) and attenuated the forskolin-induced inward current (to $22 \pm 4 \mathrm{pA} ; n=4 ; p<0.05$ ),
Depolarized

suggesting that cAMP-induced presynaptic depolarization may arise in part from an inhibition of resting potassium conductance. In the presence of $\mathrm{Cs}^{+}(1 \mathrm{~mm})$, forskolin depolarized presynaptic terminals to a similar extent $(10 \pm 3 \mathrm{mV} ; n=4)$, suggesting that $I_{\mathrm{h}}$ is not involved in the forskolin-induced presynaptic depolarization. Although the $\mathrm{Ba}^{2+}$-insensitive inward currents may arise from cAMP-gated channels, given no specific tool for its identification and because of minor contribution of presynaptic depolarization to cAMP-dependent synaptic potentiation, we did not pursue further its ionic mechanism.

\section{Potentiation of EPSCs by presynaptic loading of 8CPT-2Me-cAMP}

We next examined whether the cAMPdepedent synaptic potentiation is mediated by PKA. Consistent with a previous report, at the calyx of Held (Sakaba and Neher, 2001), neither of the PKA inhibitors H-89 $(1 \mu \mathrm{M})$ nor KT5720 $(1 \mu \mathrm{M})$ affected forskolin-induced EPSC potentiation (supplementary Fig. 1, available at www.jneurosci.org). 8CPT-2Me-cAMP is a selective agonist of Epac, with little effect on PKA (Enserink et al., 2002; Christensen et al., 2003). When we applied 8CPT-2MecAMP $(500 \mu \mathrm{M})$ into presynaptic terminals, EPSCs were potentiated by $243 \pm$ $62 \%(n=5)$ (Fig. 6). This magnitude of potentiation was even larger than that caused by cAMP, suggesting that cAMP and its analogs increase transmitter release via the PKA-independent Epac pathway, as reported for insulin secretion in pancreatic cells (Ozaki et al., 2000). Similar to cAMP (Fig. 2) or forskolin, intracellular loading of 8CPT-2Me-cAMP depolarized calyceal terminals by $10.3 \pm 1.4 \mathrm{mV}(n=5)$ (Fig. $6 A)$.

\section{The facilitatory effects of forskolin and phorbol ester are additive}

At the calyx of Held, phorbol ester facilitates transmitter release via activation of protein kinase C (PKC) and Doc $2 \alpha$-Munc13-1 interaction (Hori et al., 1999). Both Munc13-1 (Betz et al., 2001) and Epac (Ozaki et al., 2000) can interact with Rim1, raising a possibility that synaptic potentiations induced by forskolin and phorbol ester might share a common mechanism. To test this possibility, we performed occlusion experiments. Phorbol 1,2dibutrate $(\mathrm{PDBu})$ applied at its saturating concentration $(1 \mu \mathrm{M})$ (Hori et al., 1999) in addition to forskolin $(50 \mu \mathrm{M})$ also potentiated EPSCs with no sign of occlusion (Fig. 7A). The mean magnitude of potentiation caused by coapplication of PDBu and forskolin was $693 \pm 132 \%(n=7)$, which was not significantly different from the sum of individual effects of PDBu (410 $\pm 82 \%$; $n=5)$ and forskolin $(335 \pm 64 \% ; n=7)$ (Fig. 7B). These results are consistent with those reported at inhibitory synapses (Capogna et al., 1995) and suggest that the target of cAMP for synaptic potentiation is distinct from that of PKC or Munc13.

In pancreatic $\beta$ cells, cAMP-dependent activation of $\mathrm{Ca}^{2+}$. 
induced $\mathrm{Ca}^{2+}$ release (CICR) is mediated by Epac, and this effect can be blocked by ryanodine (Kang et al., 2001, 2003). To examine whether CICR is involved in the cAMP-dependent synaptic potentiation, we tested the effect of ryanodine on the forskolin-induced synaptic potentiation. In the presence of ryanodine $(30 \mu \mathrm{M})$, forskolin potentiated EPSCs by $295 \pm 56 \%$ $(n=3)$, which was similar to control (supplementary Fig. 1, available at www.jneurosci.org). Ryanodine at this concentration blocked the EPSC potentiation induced by a CICR activator at the calyx of Held (T. Yamauchi and T. Takahashi, unpublished observation). Thus, these results rule out an involvement of CICR in the cAMP-induced synaptic potentiation.

\section{Discussion}

At various synapses, it has been suggested that forskolin and membrane permeable cAMP analogs induce synaptic potentiation by a presynaptic mechanism (Salin et al., 1996; Trudeau et al., 1996; Chen and Regehr, 1997; Sakaba and Neher, 2001). In the present study, we directly demonstrated that intracellular application of cAMP into the nerve terminal markedly enhances transmitter release. These results confirm that the site of actions of forskolin and CAMP analogs is indeed presynaptic.

Involvement of both release probability and number of releasable vesicles in the cAMP-dependent synaptic potentiation

Using independent methods, the MK-801 and the highfrequency stimulation protocols, we have shown that forskolin increases the release probability, $P$, by approximately twofold. The high-frequency stimulation protocol also indicates that forskolin additionally increases the number of releasable vesicles, $N$. In cerebellar parallel fiber-Purkinje cell synapse, the effect of forskolin has been attributed primarily to an increase in $P$ (Chen and Regehr, 1997). In contrast, at the calyx of Held, presynaptic cAMP is proposed to selectively increase the number of vesicles having high-release probability, because forskolin-induced synaptic potentiation is observed only at the early phase of EPSCs evoked by a sustained presynaptic $\mathrm{Ca}^{2+}$ current (Sakaba and Neher, 2001). Also, in our study, forskolin preferentially enhanced the first few EPSCs during a train of tetanic stimulation. In the MK-801 experiments, bi-exponential decay time course is thought to reflect vesicle populations having different release probabilities (Rosenmund et al., 1993). In our experiments, forskolin accelerated the fast decay time constant and increased the relative proportion of the fast decaying component, suggesting that forskolin increases $P$ and the proportion of vesicles with high $P$ as proposed previously (Sakaba and Neher, 2001).

\section{Target of cAMP for synaptic potentiation}

It was not known whether forskolin affects voltage-dependent ion channels in the nerve terminal. Our present results indicate that forskolin has no effect on the voltage-dependent $\mathrm{Ca}^{2+}$ currents recorded from calyceal presynaptic terminals. Forskolin
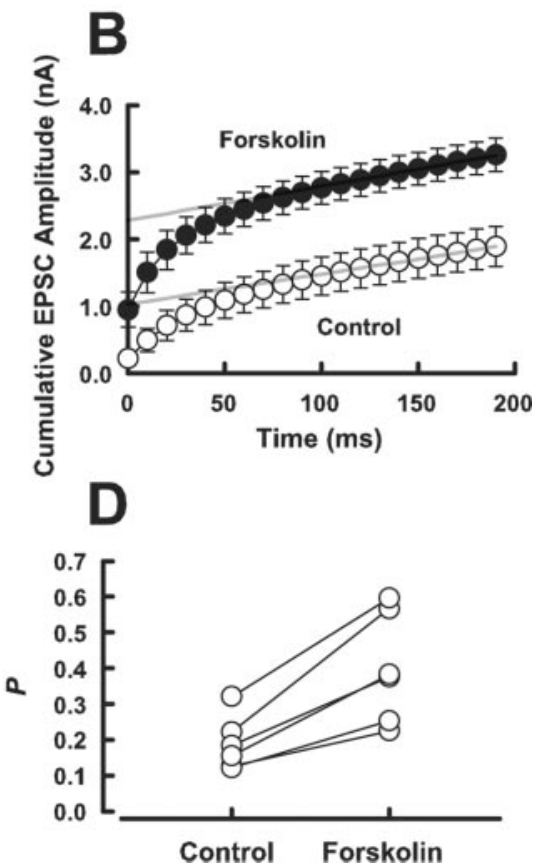

Control Forskolin

Figure 3. Forskolin increases both the number of releasable vesicles and release probability. $A$, Depressions of EPSCS during

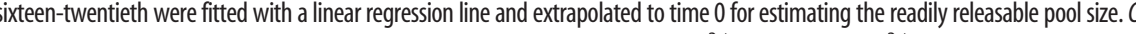
ratio of the first EPSC amplitude divided by $N q$, underwent a significant increase $(p<0.05)$ after forskolin application $(n=6)$.

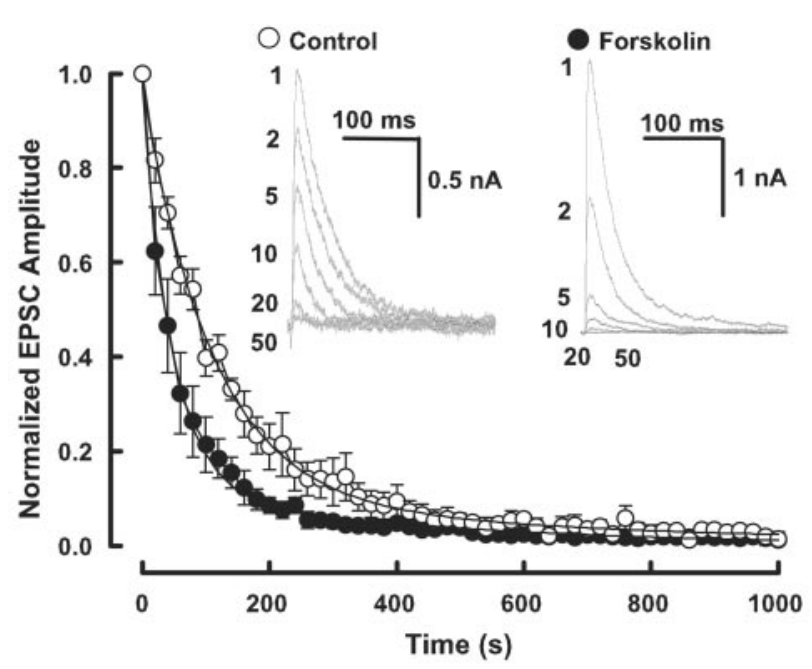

Figure 4. Forskolin accelerates the time course of block of NMDA-EPSCs by MK-801. NMDA EPSCs were evoked at $0.033 \mathrm{~Hz}$ at a holding potential of $+40 \mathrm{mV}$ in the presence of MK-801 (40 $\mu \mathrm{m})$. Data are derived from a different group of cells, one group in the presence of forskolin (50 $\mu \mathrm{m}$; filled circles; $n=5$ ) and the other in its absence (open circles; $n=5$ ). The numbers on sample traces (superimposed) indicate the sequence of stimulation (1-50). Ordinate indicates the amplitude of NMDA-EPSCs normalized to the initial amplitude. Abscissa indicates the time after starting stimulation in the presence of MK-801. Mean relative amplitudes derived each from five cells were fitted with double exponential functions.

also had no effect on the peak amplitude of the voltagedependent $\mathrm{K}^{+}$currents. Although forskolin attenuated slow components of presynaptic $\mathrm{K}^{+}$currents, it would not affect $\mathrm{Ca}^{2+}$ influx evoked by a presynaptic action potential. Although forsko- 


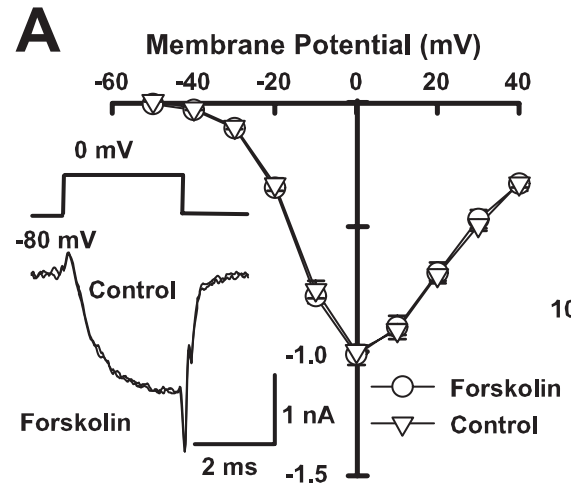

Normalized Current
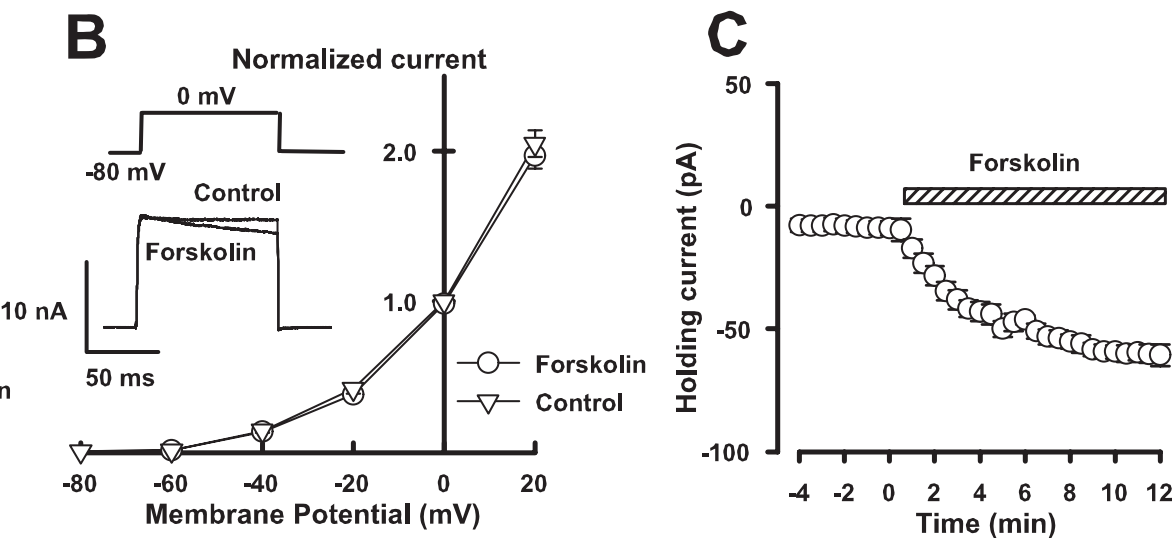

Figure 5. Effects of forskolin on presynaptic $\mathrm{Ca}^{2+}$ currents, $\mathrm{K}^{+}$currents, and holding currents. $A$, The current-voltage relationships of $\mathrm{Ca}^{2+}$ currents before (circles) and after (triangles) forskolin application (superimposed). The $\mathrm{Ca}^{2+}$ current amplitude was measured at $1.5 \mathrm{msec}$ from the depolarizing command pulse onset and normalized to the value at $0 \mathrm{mV}$. Forskolin ( $50 \mu \mathrm{m}$ ) had no effect on the voltage-dependent $\mathrm{Ca}^{2+}$ currents, as also shown in completely overlapped sample records before and after forskolin application. $B$, The current-voltage relationships of $\mathrm{K}^{+}$ currents before (circles) and after (triangles) forskolin application. The $\mathrm{K}^{+}$current amplitude was measured at $10 \mathrm{msec}$ from the depolarizing pulse onset. Sample records show the effect of forskolin accelerating the decay of $\mathrm{K}^{+}$current amplitude during the depolarizing pulse. C, The effect of forskolin on the presynaptic holding current ( $n=4$; error bars merge into symbols) measured at the holding potential of $-80 \mathrm{mV}$ (after correcting the liquid junction potential of $11.6 \mathrm{mV}$ ).

A
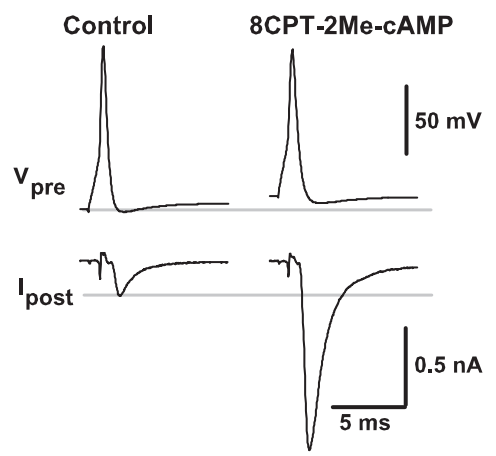
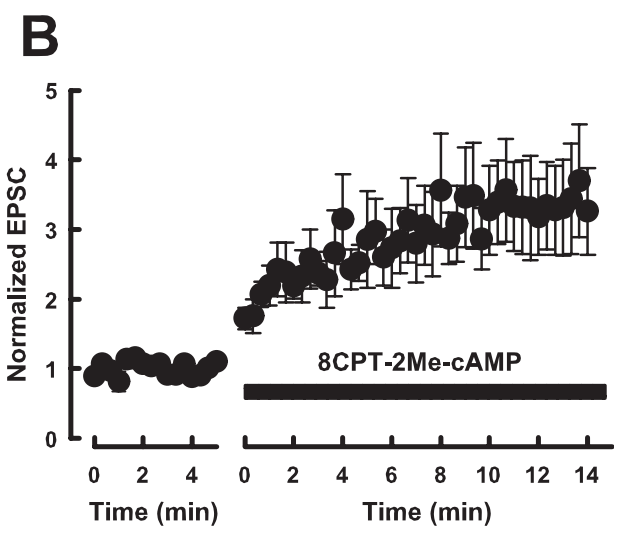

Figure 6. Potentiation of EPSCs by presynaptic loading of 8CPT-2Me-CAMP. In simultaneous presynaptic and postsynaptic recordings, 8CPT-2Me-cAMP (500 $\mu \mathrm{M}$ ) was loaded into the calyceal terminal by replacing the presynaptic pipette. A, Averaged sample records (from 10 events each) of presynaptic action potentials and EPSCs before and after 8CPT-2Me-CAMP application. 8CPT-2Me-CAMP enhanced EPSCs and slightly depolarized presynaptic terminal. Lines indicate control resting potential level (top column) and EPSC amplitude (bottom column). B, Summary data of five experiments showing the potentiation of EPSCs by presynaptically loaded 8CPT-2Me-CAMP.
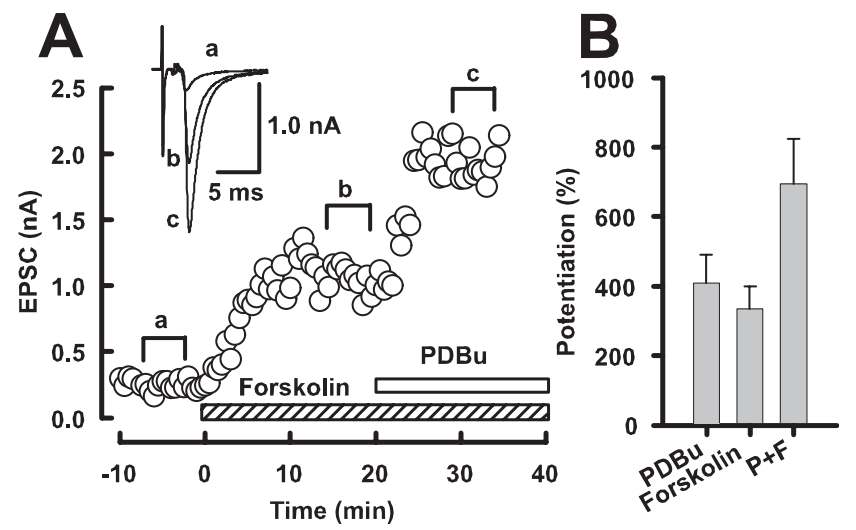

Figure 7. Coapplication of forskolin and phorbol ester. $A$, Forskolin $(50 \mu \mathrm{m})$ potentiated $\operatorname{EPSCS}(a, b)$. Addition of PDBu $(1 \mu \mathrm{m})$ further potentiated EPSCS ( $c)$. Sample records are averaged EPSCs (from 5 events) taken from different epochs ( $a, b, c$, superimposed). $B$, Mean magnitude of EPSC potentiation by PDBu alone (PDBu), forskolin alone (Forskolin), and PDBu plus forskoin (P+F). The magnitude of potentiation by PDBu plus forskolin $(693 \pm 132 \% ; n=7)$ is similar to the sum of potentiations by PDBu $(410 \pm 82 \% ; n=5)$ and forskolin $(335 \pm 64 \% ; n=7)$. lin, cAMP, and 8CPT-2Me-cAMP all depolarized the nerve terminal, the contribution of presynaptic depolarization to synaptic potentiation was minor. Given that forskolin increases both $N$ and $P$, the target of cAMP for synaptic potentiation seems to be in both the vesicular trafficking mechanism and the exocytotic mechanisms. In this respect, Sakaba and Neher (2003) reported that cAMP or 8CPT-2Me-cAMP, when loaded into the calyceal presynaptic terminal, accelerates recovery of synaptic currents from post-tetanic depression, which had been slowed in the presence of baclofen or GDP $\beta$ S. However, given that cAMP by itself has no effect on the recovery time, this phenomenon must be distinct from the direct facilitatory effect of cAMP on transmitter release shown here.

What is the molecular target of cAMP? Unlike other synapses (Chavez-Noriega and Stevens, 1994; Weisskopf et al., 1994; Capogna et al., 1995; Salin et al., 1996; Trudeau et al., 1996), PKA inhibitors have no effect on forskolin-induced synaptic potentiation at the calyx of Held (Sakaba and Neher, 2001; our study). Furthermore, presynaptic loading of 8CPT-2Me-cAMP, a selective agonist for Epac (Enserink et al., 2002; Christensen et al., 2003), strongly potentiated EPSCs, suggesting that Epac mediates cAMP-dependent facilitation of transmitter release as recently reported for insulin secretion in pancreatic cells (Ozaki et al., 2000; Kashima et al., 2001; Eliasson et al., 2003). Epac, a guanine nucleotide-exchanging factor for small GTPases, is a direct target of cAMP (Bos, 2003). Epac binds cAMP with a half-maximal activation at $40 \mu \mathrm{M}$, which is higher than that of cAMP required for PKA activation $(1 \mu \mathrm{M})$ (de Rooij et al., 2000; Rehmann et al., 2003). This may explain the lack of effect of cAMP loaded at 10 $\mu \mathrm{M}$ into the calyces. Epac activates Rap1 and Rap2, ryanodine receptors, and interacts with Rims. The cAMP-dependent enhancement of insulin secretion is mediated by Epac2 via interaction with Rim2 (Ozaki et al., 2000; Kashima et al., 2001; Eliasson et al., 2003). The Rim family is located in the active zone and 
thought to be involved in the priming step of synaptic vesicle fusion (Wang et al., 2000; Castillo et al., 2002; Schoch et al., 2002). The most abundant form of Rim in the neuronal system is Rim1. In the Rim1 knock-out mice, however, forskolin-induced synaptic potentiation at the hippocampal synapse is unaffected (Castillo et al., 2002). Thus, Rim1 may not be a target of the cAMP-induced (PKA-independent) synaptic potentiation. An involvement of Rim2, which is also expressed in the neuronal system (Wang et al., 2000), remains as a possibility.

Epacs can increase intracellular $\mathrm{Ca}^{2+}$ concentration via activating ryanodine receptors, thereby facilitating exocytosis (Kang et al., 2001, 2003). However, our results using ryanodine rule out the involvement of this mechanism in cAMP-dependent synaptic potentiation. Thus, the molecular target downstream of Epac remains to be determined. Expression of Epac1 mRNA is high in some parts of the neonatal brain but low in the adult brain, whereas Epac2 transcripts are strongly expressed in both the mature and neonatal brain (Kawasaki et al., 1998). Thus, the developmental decline of forskolin-induced synaptic potentiation might arise from that of target proteins.

\section{References}

Bailey CH, Bartsch D, Kandel ER (1996) Toward a molecular definition of long-term memory storage. Proc Natl Acad Sci USA 93:13445-13452.

Beaumont V, Zucker RS (2000) Enhancement of synaptic transmission by cAMP modulation of presynaptic $I_{\mathrm{h}}$ channels. Nat Neurosci 3:133-141.

Betz A, Thakur P, Junge HJ, Ashery U, Rhee JS, Scheuss V, Rosenmund C, Rettig J, Brose N (2001) Functional interaction of the active zone proteins Munc13-1 and RIM1 in synaptic vesicle priming. Neuron 30:183-196.

Bos JL (2003) Epac: a new cAMP target and new avenues in cAMP research. Nat Rev Mol Cell Biol 4:733-738.

Capogna M, Gahwiler BH, Thompson SM (1995) Presynaptic enhancement of inhibitory synaptic transmission by protein kinases $\mathrm{A}$ and $\mathrm{C}$ in the rat hippocampus in vitro. J Neurosci 15:1249-1260.

Castillo PE, Schoch S, Schmitz F, Sudhof TC, Malenka RC (2002) Rim $1 \alpha$ is required for presynaptic long-term potentiation. Nature 415:327-330.

Chavez-Noriega LE, Stevens CF (1994) Increased transmitter release at excitatory synapses produced by direct activation of adenylate cyclase in rat hippocampal slices. J Neurosci 14:310-317.

Chen C, Regehr WG (1997) The mechanism of cAMP-mediated enhancement at a cerebellar synapse. J Neurosci 17:8687-8694.

Christensen AE, Selheim F, de Rooij J, Dremier S, Schwede F, Dao KK, Martinez A, Maenhaut C, Bos JL, Genieser HG, Doskeland SO (2003) cAMP analog mapping of Epac1 and cAMP kinase. J Biol Chem 278:35394-35402.

de Rooij J, Rehmann H, van Triest M, Cool RH, Wittinghofer A, Bos JL (2000) Mechanism of regulation of the Epac family of cAMP-dependent RapGEFs. J Biol Chem 275:20829-20836.

Eliasson L, Ma X, Renstrom E, Barg S, Berggren P, Galvanovskis J, Gromada J, Jing X, Lundquist I, Salehi A, Sewing S, Rorsman P (2003) SUR1 regulates PKA-independent cAMP-induced granule priming in mouse pancreatic B-cells. J Gen Physiol 121:181-197.

Enserink JM, Christensen AE, de Rooij J, van Triest M, Schwede F, Genieser HG, Doskeland SO, Blank JL, Bos JL (2002) A novel Epac-specific cAMP analogue demonstrates independent regulation of Rap1 and ERK. Nat Cell Biol 4:901-906.

Forsythe ID, Barnes-Davies M (1993) The binaural auditory pathway: excitatory amino acid receptors mediate dual timecourse excitatory postsynaptic currents in the rat medial nucleus of the trapezoid body. Proc R Soc Lond B Biol Sci 251:151-157.

Hessler NA, Shirke AM, Malinow R (1993) The probability of transmitter release at a mammalian central synapse. Nature 366:569-572.

Hori T, Takai Y, Takahashi T (1999) Presynaptic mechanism for phorbol ester-induced synaptic potentiation. J Neurosci 19:7262-7267.
Ishikawa T, Sahara Y, Takahashi T (2002) A single packet of transmitter does not saturate postsynaptic glutamate receptors. Neuron 34:613-621.

Iwasaki S, Takahashi T (2001) Developmental regulation of transmitter release at the calyx of Held in rat auditory brainstem. J Physiol (Lond) 534:861-871.

Kang G, Chepurny OG, Holz GG (2001) cAMP-regulated guanine nucleotide exchange factor II (Epac2) mediates $\mathrm{Ca}^{2+}$-induced $\mathrm{Ca}^{2+}$ release in INS-1 pancreatic $\beta$-cells. J Physiol (Lond) 536:375-385.

Kang G, Joseph JW, Chepurny OG, Monaco M, Wheeler MB, Bos JL, Schwede F, Genieser HG, Holz GG (2003) Epac-selective cAMP analog 8-pCPT$2^{\prime}-\mathrm{O}$-Me-cAMP as a stimulus for $\mathrm{Ca}^{2+}$-induced $\mathrm{Ca}^{2+}$ release and exocytosis in pancreatic $\beta$-cells. J Biol Chem 278:8279-8285.

Kashima Y, Miki T, Shibasaki T, Ozaki N, Miyazaki M, Yano H, Seino S (2001) Critical role of cAMP-GEFII-Rim2 complex in incretinpotentiated insulin secretion. J Biol Chem 276:46046-46053.

Kawasaki H, Springett GM, Mochizuki N, Toki S, Nakaya M, Matsuda M, Housman DE, Graybiel AM (1998) A family of cAMP-binding proteins that directly activate Rap1. Science 282:2275-2279.

Ozaki N, Shibasaki T, Kashima Y, Miki T, Takahashi K, Ueno H, Sunaga Y, Yano H, Matsuura Y, Iwanaga T, Takai Y, Seino S (2000) cAMP-GEFII is a direct target of cAMP in regulated exocytosis. Nat Cell Biol 2:805-811.

Rehmann H, Prakash B, Wolf E, Rueppel A, de Rooij J, Bos JL, Wittinghoher A (2003) Structure and regulation of the cAMP-binding domains of Epac2. Nat Struct Biol 10:26-32.

Rosenmund C, Clements JD, Westbrook GL (1993) Nonuniform probability of glutamate release at a hippocampal synapse. Science 262:754-757.

Sakaba T, Neher E (2001) Preferential potentiation of fast-releasing synaptic vesicles by cAMP at the calyx of Held. Proc Natl Acad Sci USA 98:331-336.

Sakaba T, Neher E (2003) Direct modulation of synaptic vesicle priming by $\mathrm{GABA}_{\mathrm{B}}$ receptor activation at a glutamatergic synapse. Nature 424:775-778.

Salin PA, Malenka RC, Nicoll RA (1996) Cyclic AMP mediates a presynaptic form of LTP at cerebellar parallel fiber synapses. Neuron 16:797-803.

Schneggenburger R, Meyer AC, Neher E (1999) Released fraction and total size of a pool of immediately available transmitter quanta at a calyx synapse. Neuron 23:399-409.

Schoch S, Castillo PE, Jo T, Mukherjee K, Geppert M, Wang Y, Schmitz F, Malenka RC, Sudhof TC (2002) Rim $1 \alpha$ forms a protein scaffold for regulating neurotransmitter release at the active zone. Nature 415:321-326.

Silva AJ, Kogan JH, Frankland PW, Kida S (1998) CREB and memory. Annu Rev Neurosci 21:127-148.

Takahashi T, Kajikawa Y, Tsujimoto T (1998) G-protein-coupled modulation of presynaptic calcium currents and transmitter release by a $\mathrm{GABA}_{\mathrm{B}}$ receptor. J Neurosci 18:3138-3146.

Taschenberger H, von Gersdorff H (2000) Fine-tuning an auditory synapse for speed and fidelity: developmental changes in presynaptic waveform, EPSC kinetics, and synaptic plasticity. J Neurosci 20:9162-9173.

Taschenberger H, Leao RM, Rowland KC, Spirou GA, von Gersdorff $\mathrm{H}$ (2002) Optimizing synaptic architecture and efficiency for highfrequency transmission. Neuron 36:1127-1143.

Trudeau LE, Emery DG, Haydon PG (1996) Direct modulation of the secretory machinery underlies PKA-dependent synaptic facilitation in hippocampal neurons. Neuron 17:789-797.

Turecek R, Trussel LO (2001) Presynaptic glycine receptors enhance transmitter release at a mammalian central synapse. Nature 411:587-590.

Wang Y, Sugita S, Sudhof TC (2000) The RIM/NIM family of neuronal $C_{2}$ domain proteins. J Biol Chem 275:20033-20044.

Weisskopf MG, Castillo PE, Zalutsky RA, Nicoll RA (1994) Mediation of hippocampal mossy fiber long-term potentiation by cyclic AMP. Science 265:1878-1882.

Wong AYC, Graharm BP, Billups B, Forsythe ID (2003) Distinguishing between presynaptic and postsynaptic mechanisms of short-term depression during action potential trains. J Neurosci 23:4868-4877.

Yamashita T, Ishikawa T, Takahashi T (2003) Developmental increase in vesicular glutamate content does not cause saturation of AMPA receptors at the calyx of Held synapse. J Neurosci 23:3633-3638. 